\title{
Neonatal hypoglycemia: do we know what to do?
}

\author{
Volume 4 Issue 2 - 2016 \\ Guillermo Godoy \\ Department of Pediatrics and Obstetrics, University of Alabama, \\ USA
}

\section{Editorial}

Neonatal hypoglycemia has had a simple definition since 1965 , when Cornblath in a N Engl J Med manuscript, stated that neonatal hypoglycemia in low-birth weight infants has a plasma level equal or less than $25 \mathrm{mg}$ (milligrams)/dl and equal or less than $35 \mathrm{mg} / \mathrm{dl}$ in term babies. ${ }^{1}$ This article follows the seminal report of symptomatic neonatal hypoglycemia associated with toxemia of pregnancy. ${ }^{2}$

Since then, the clear and easy diagnosis and treatment of neonatal hypoglycemia has become progressively more convoluted and unclear. ${ }^{3-5}$ The AAP through The Committee on Fetus and Newborn reaffirms that there is no evidence at the present time to support a specific concentration of glucose that can discriminate normal from abnormal values that will automatically predict neurodevelopmental impairment. $^{5}$

On the other hand, there is evidence that congenital hyperinsulinism continues to have the same incidence of permanent brain damage as it did 40years ago. ${ }^{6}$

Recently, Harris et al. in 2012 and McKinlay C \& Felig P, et al. in $2015,{ }^{7,8}$ stated that to prevent neurodevelopmental compromise secondary to hypoglycemia, the glucose serum concentration at the laboratory may be kept equal or above $47 \mathrm{mg} / \mathrm{dl} .^{3}$ This was followed by commentaries from several glucose metabolism experts. These experts stated that the Harris and McKinlay studies were observational and the $47 \mathrm{mg} / \mathrm{dl}$ threshold was chosen at random. Also these studies were based on some evidence that glucose levels below $45 \mathrm{mg} / \mathrm{dl}$, in some circumstances, were associated with neurodevelopmental impairment. ${ }^{7,8}$

It seems to be a multitude of factors that should be considered when assessing an infant with possible hypoglycemia. It is these factors that could lead to neurodevelopmental injury.

\section{Let's review a few facts revealed by early studies concerning glucose metabolism in neonates}

Neonates do not suppress their plasma insulin levels during transitional hypoglycemia. This may be secondary and necessary to support the rapid fetal growth. ${ }^{9}$

The glucose concentration in newborns drops to a nadir around $55 \mathrm{mg} / \mathrm{dl}$ at approximately 2 hours after birth. Then, glucose levels steadily increase to older children levels of around $70-90 \mathrm{mg} / \mathrm{dl}$ by day 4 of postnatal life. ${ }^{10}$

There is a well-documented normal activation of glucagon and a normal elevation of epinephrine levels in babies small for gestational age and healthy newborns with decreasing levels of plasma glucose. ${ }^{11-13}$
Correspondence: Guillermo Godoy, Department of Pediatrics and Obstetrics, University of Alabama, I 364 Downing Ridge, Tuscaloosa, Al 35406, USA, Tel 205-752-9739, Fax 205-345-5277, Email guillermo46I@comcast.net

Received: January 21, 2016 | Published: February 03, 2016

Furthermore, newborns do not breakdown fatty acids to ketones; so newborn brains could not utilize effectively ketones as an alternative brain fuel source. ${ }^{10,11}$

The Reaffirmation of the policy from the American Academy of Pediatrics in 2011 states that in asymptomatic normal newborns, transient hypoglycemia in the first few hours after birth is considered to be part of the normal adaption to post natal life ${ }^{5}$

\section{So, where do we go from here?}

In my personal opinion, and with the knowledge available to us at the present time, I propose the following:

\section{First, we need to categorize hypoglycemia in infants:}

i. Normal, late preterm, and term asymptomatic infants.

ii. High risk infants with asymptomatic hypoglycemia.

iii. Newborns at risk for hypoglycemia due to perinatal events.

iv. Symptomatic hypoglycemic newborns.

1. Normal, late preterm, and term asymptomatic infants, that are appropriate weight-for gestational age, should not be screened for hypoglycemia unless they fulfill one or two of the criteria below.

2. High-risk asymptomatic infants include: preterm infants less than 34 weeks gestational age. Post-mature infants, small-forgestational age infants, cold stressed infants, septic infants, babies with congenital heart disease and/or respiratory distress, infants with hypoxic ischemic insults and acidotic infants.

3. Risks due to perinatal events such as: Abruptio placenta, cord accident, placenta Previa, uterine rupture, mothers with diabetes, mothers with pregnancy induced hypertension, mothers with hyperthyroidism and babies born to drug addicted mothers.

The above three groups should be screened within the first hour after birth. All infants should be fed at one hour after birth and check 
glucose level 30minutes after feeding. Then, feed every 2 to 3 hours and follow glucose levels one hour after each feeding, up to thours. After 4hours of age, check glucose levels before each feeding, every 2 to 3 hours.

Glucose levels should continue to be checked for at least 24hours in infants with poor storages (small for gestational age, hyperinsulinemia states, septic infants, and newborns with respiratory or cardiac conditions, shock or encephalopathies. In these infants, the risks of hypoglycemia could persist up to 10days.

Infants of diabetic mothers, present with low glucose levels soon after birth. Most of them, will present with low glucose levels, within 12 hours after birth.

If glucose levels are less than $40 \mathrm{mg} / \mathrm{dl}$ in an asymptomatic baby, he/she should be treated immediately with oral feedings. If the glucose level does not increase above $40 \mathrm{mg} / \mathrm{dl}$, the infant should receive an IV glucose bolus at a dose of $200 \mathrm{mg} / \mathrm{Kg}$, or $2 \mathrm{ml} / \mathrm{Kg}$ of D $10 \mathrm{~W}$ as soon as possible, followed by feedings.

In symptomatic hypoglycemic babies, a dose of IV glucose bolus should be given immediately, followed by a constant IV glucose infusion of at least $6 \mathrm{mg} / \mathrm{Kg} /$ minute, to maintain glucose levels above $40 \mathrm{mg} / \mathrm{dl}$.

Any infant with a response to IV glucose of less than $40 \mathrm{mg} / \mathrm{dl}$ should receive another bolus and may need to increase IV glucose concentration in the IV infusion. This means that from the baseline glucose usage of 4 to $6 \mathrm{mg} / \mathrm{Kg} /$ minute, the patient may need above $9 \mathrm{mg} /$ $\mathrm{Kg} /$ minute. The boluses and constant glucose infusion concentration could be progressively increased up to $\mathrm{D} 12.5 \mathrm{~W}$ in a peripheral IV catheter and up to D25W in a central venous placed catheter.

Generally speaking, infants that required more than $\mathrm{D} 12.5 \mathrm{~W}$ or $9-10 \mathrm{mg}$ of glucose $/ \mathrm{Kg} /$ minute to maintain glucose levels above $40 \mathrm{mg} / \mathrm{dl}$ after 72 hours (approximately of birth should have further endocrinology consultation and endocrinology work up. Newborns that are severely growth retarded and babies of poorly controlled diabetic mothers tend to have a protracted high glucose requirements time until the glucose levels stabilized.

Also, these infants may require further therapy to reach glucose levels above $40 \mathrm{mg} / \mathrm{dl}$, such as diazoxide and IV steroids.

During the initial period of symptomatic hypoglycemia, or glucose levels less than $30 \mathrm{mg} / \mathrm{dl}$, the use of glucagon should be considered while an IV access is obtained.

In certain groups of infants at very high risk of hypoglycemia, a glucose level should be obtained within 30 minutes after birth. These groups of infants include: infants born less than 28 weeks gestation, hypoxic ischemic encephalopathic babies and newborns in shock and/ or significant acidosis. They may have glucose levels less than $25 \mathrm{mg} /$ $\mathrm{dl}$ in this short period of time.

I have addressed the term "glucose levels" intentionally. We know that levels less than $40 \mathrm{mg} / \mathrm{dl}$ obtained by bedside devices underestimate the glucose concentration. We should send a STAT glucose sample to the central laboratory that will run an enzymatic method to confirm the value obtained by the bedside devise. ${ }^{14}$

I suggest not waiting for the confirmatory result from the central laboratory, to start treatment if glucose level is less than $40 \mathrm{mg} / \mathrm{dl}$.
I suggest following the flow chart presented by the Committee on Fetus and Newborn for screening and management of hypoglycemia. ${ }^{5}$

This is my opinion with the present available data. We should continue to be vigilant about new information that could prevent symptomatic hypoglycemia and minimize or prevent neurodevelopmental injuries in the newborn population.

\section{Acknowledgments}

None.

\section{Conflicts of interest}

Author declares there are no conflicts of interest.

\section{Funding}

None.

\section{References}

1. Cornblath M, Reisner SH. Blood glucose in the neonate and its clinical significance, N Engl J Med. 1965;273(7):378-381.

2. Cornblath M, Odell GB, Levin EY. Symptomatic neonatal hypoglycemia associated with toxemia of pregnancy. J Pediatr . 1959;55:545.

3. Harris DL, Weston PJ, Harding JE. Incidence of neonatal hypoglycemia in babies identified as at risk. J Pediatr. 2012;161(5): 787-791.

4. Hay WW Jr, Raju TN, Higgins RD, et al. Knowledge gaps and research needs for understanding and treating neonatal hypoglycemia: workshop report from Eunice Kennedy Shriver National Institute of Child Health and Human development. J Pediatr . 2009;155(5):612-617.

5. Committee on Fetus and Newborn, Adamkin DH. Postnata glucose homeostasis in late-preterm and term infants. Pediatrics. 2011;127(3):575-579.

6. Menni F, de Lonlay P, Sevin C, et al. Neurologic outcomes of 90 neonates and infants with persistent hyperinsulinemic hypoglycemia. Pediatrics. 2001;107(3): 476-479.

7. Cornblath M, Hawdon JM, Williams AF, et al. Controversies Regarding Definition of Neonatal Hypoglycemia: Suggested Operational Thresholds. Pediatrics. 2005;105(5):1141-1145.

8. McKinlay CJ, Alsweiler JM, Ansell JM, et al. Neonatal Glycemia and neurodevelopmental Outcomes at 2 Years. $N$ Engl J Med. 2015;373(16):1507-1518.

9. Felig P, Lynch V. Starvation in human pregnancy: hypoglycemia hypoinsulinemia, and hyperketonemia. Science. 1970;170(3961): 990-992.

10. Howdon JM, Ward MP, Aynsley-Green A. Patterns of metabolic adaptation for preterm and term infants in the first neonatal week. Arch Dis Child. 1992;67(4 Spec No):357-365.

11. Haymond MW, Karl IE, Pagliara AS. Increased gluconeogenesis substrates in the small-for-gestational-age infant. $N$ Engl $\mathrm{J} \mathrm{Med}$. 1974;291(7): 322-328

12. Cryer PE. Hypoglycemia in diabetes: Pathophysiology, prevalence, and prevention. American Diabetes Association. Alexandria VA. 2009.

13. Swenne I, Ewald U, Gustafsson J, et al. Inter-relationship between serum concentrations of glucose, glucagon and insulin during the first two days of life in healthy newborns. Acta Pediatr. 1994; 83(9):915-919.

14. Aynsley-Green A. Glucose: a fuel for thought! J Pediatr Child Health 1991;27(1):21-30. 